\title{
Preparation of platinum/iridium scanning probe microscopy tips
}

\author{
Sørensen, Alexis Hammer; Hvid, U.; Mortensen, M.W.; Mørch, Knud Aage
}

Published in:

Review of Scientific Instruments

Link to article, DOI:

$10.1063 / 1.1149891$

Publication date:

1999

Document Version

Publisher's PDF, also known as Version of record

Link back to DTU Orbit

Citation (APA):

Sørensen, A. H., Hvid, U., Mortensen, M. W., \& Mørch, K. A. (1999). Preparation of platinum/iridium scanning probe microscopy tips. Review of Scientific Instruments, 70(7), 3059-3067. https://doi.org/10.1063/1.1149891

\section{General rights}

Copyright and moral rights for the publications made accessible in the public portal are retained by the authors and/or other copyright owners and it is a condition of accessing publications that users recognise and abide by the legal requirements associated with these rights.

- Users may download and print one copy of any publication from the public portal for the purpose of private study or research.

- You may not further distribute the material or use it for any profit-making activity or commercial gain

- You may freely distribute the URL identifying the publication in the public portal

If you believe that this document breaches copyright please contact us providing details, and we will remove access to the work immediately and investigate your claim. 


\title{
Preparation of platinum/iridium scanning probe microscopy tips
}

\author{
A. H. Sørensen, U. Hvid, M. W. Mortensen, and K. A. Mørch ${ }^{\text {a) }}$ \\ Department of Physics, Technical University of Denmark, Building 307, DK-2800 Lyngby, Denmark
}

(Received 3 February 1998; accepted for publication 25 March 1999)

We report on the development of an etching setup for use in the preparation of platinum/iridium tips for atomic force microscopy and scanning electrostatic force microscopy as well as scanning tunneling microscopy. The etching process is based on a two step electrochemical procedure. The first step is a coarse alternating current (ac) etching in which the etching is continuous and stops automatically when the lower part of the wire drops off, while the second step is a fine etching made by a number of ac pulses, each of a certain duration and separated by a certain interval of time. When the tip material being etched is platinum/iridium (10\%) the influence of the stop phase of the ac current terminating each pulse in the second etching is found to be negligible, while in the case of second etching of tungsten wires it is important to break the pulse in a certain phase to avoid formation of a thick oxide layer. In order to explain the relatively high etching rates observed for the otherwise noble metal platinum we suggest that besides anodic corrosion of the platinum by the electrolyte containing chloride ions, a different etching mechanism causes a substantial increase of the etching rate. This mechanism is based on the formation of oxygen and hydrogen at the platinum/ iridium electrode when the potential is above the dissociation potential of water $(\sim 1.23 \mathrm{~V})$ and storage of these products interstitially in the outer layers of the platinum wire. This leads to "microexplosions" that detach fragments of platinum from the wire surface and hereby give rise to "etching" of the wire. In the second etching blunt tips become sharp while tips which are already sharp apparently stay sharp. Therefore, the second etching scheme with pulses separated by pauses is found to be a very important factor for the production of sharp tips. After being etched the tips are ready for use in scanning tunneling microscopes, or they may be bent to form integrated tip/cantilever systems in ordinary commercial atomic force microscopes, being applicable as tapping mode tips and as electrostatic force microscopy tips. (C) 1999 American Institute of Physics. [S0034-6748(99)01207-1]

\section{INTRODUCTION}

This article is concerned with the production of scanning probe microscopy tips from wires of platinum/iridium. Their mounting in a scanning tunneling microscope (STM) is straightforward, while for atomic force microscopy (AFM) and scanning electrostatic force microscopy (SEFM) they have to be bent and given a reflecting cantilever facet.

The art of preparing sharp tips for scanning tunneling microscopy is fairly developed already, ${ }^{1-9}$ and many different methods have been used in the course of time. Two common ways of tip preparation are simply cutting the wire with a wire cutter or by electrochemical etching. The choice of method depends, among other things, on the metal from which the tips are made and on the environment the tip is going to be used in. Cutting tips with a wire cutter is applicable only when very flat surfaces are investigated because a cut tip is very jagged. ${ }^{2}$ The electrochemical etching, though a slower process than mere cutting, is preferred when corrugated surfaces are to be investigated because it provides a tip with a much more controlled shape at the tip apex than cutting does. If formation of oxide on the tip is negligible during operation, as in ultrahigh vacuum, most people use in situ cleaned tungsten tips because they are very easy to etch,

${ }^{a)}$ Electronic mail: morch@fysik.dtu.dk while in ambient air or in liquid tips from platinum/iridium are preferable for STM experiments in order to prevent the tip-sample gap from being destroyed by the formation of oxide. In this article we present results obtained by electrochemical etching of platinum/iridium wires.

When measuring micrometer-sized charge distributions on insulating surfaces by means of an atomic force microscope, a conductive cantilever and tip are needed to achieve a fast and immediate reaction to the surface charge distributions underneath the tip apex. ${ }^{10,11}$ There are different ways of obtaining conductive atomic force microscopy cantilevers. One way is to coat a nonconducting cantilever with a thin metallic film, which may consist of platinum or a chromium/ gold alloy. However, if an evaporation chamber or sputtering source are not available, it may be a good idea to look for other cantilever-tip production schemes. In Refs. 10 and 11 a new tip production scheme is proposed: a scanning tunneling microscope tip is simply bent at an angle of $90^{\circ}$, the upper part of the STM tip shaft thereby forming a cantilever and the lower part of the tip shaft forming a shank with the tip apex. The advantage of this construction is that it is very simple and fairly easy to produce without advanced equipment. Further, if the bending of the STM tip is performed some hundreds of micrometers away from the tip apex, the 
cantilever will be sufficiently far away from charges on the surface to make its geometrical shape without significance for the quantitative evaluation of the size of the surface charge. The electric field originating from the surface charges then mainly creates image charges in the outermost region of the tip being close to the charges. This tip shape can be approximated by a hyperboloid ${ }^{10}$ thus facilitating the quantitative evaluation of the electric field strength. If one uses a coated standard AFM cantilever, the cantilever is usually only a few micrometers above the surface, and therefore a quantitative evaluation of the charges on the surface must take into account the geometrical shape of the cantilever due to its proximity to the surface charges.

When the scheme of a bent STM tip is utilized the tip first has to be etched, then the $90^{\circ}$ bending of the tip is made. The subsequent preparation of the tip for mounting in the atomic force microscope depends on how the microscope detects the deflections of the cantilever beam. The detection schemes usually used are interferometric ones, ${ }^{12-15}$ or it is the simple deflection detection system based on a position sensitive detector. ${ }^{16,17}$ We use the latter one in our electrostatic field measurements.

\section{EXPERIMENTAL PROCEDURE}

\section{A. Setup}

Our etching setup is developed from the etching setup first used by Song et al., ${ }^{7}$ and it operates with two etching steps of the Pt/Ir wire, a coarse first etching and a finer second etching, which are carried out in the same apparatus. The setup is shown in Fig. 1.

The Pt/Ir wire, which for our purposes is of diameter $0.25 \mathrm{~mm}$, is mounted in the brass wire holder $\mathrm{S}$, where it is fixed with a screw. A sufficient length of wire protrudes from $\mathrm{S}$ to allow it to pass through a layer of electrolyte, typically about 4-5 mm thick which floats on top of an insulating liquid, and into a mercury drop contained in an acid resistant stainless steel cup placed beneath $\mathrm{S}$ in the insulating liquid. Copper wires from the cup to the brass support rod, and from this rod to the power supply establish the electrical connection between the $\mathrm{Pt} / \mathrm{Ir}$ electrode and the power supply phase terminal. A counter electrode $\mathrm{C}$ made from eight long, thin graphite rods, mounted in a circular arrangement of diameter $40 \mathrm{~mm}$ on the brass holder $\mathrm{R}$ above the electrolyte, passes through the electrolyte layer symmetrically around the Pt/Ir electrode and it is electrically connected to the ground terminal of the power supply. Etching occurs only on the part of the wire being in contact with the electrolyte. If desired, the part of the wire right beneath $\mathrm{S}$ may be electrically shielded by a teflon tube, which is sharpened to allow gas bubbles to escape. Hereby it is possible to adjust the length of the wire being in contact with the electrolyte by the micrometer screw $\mathrm{M}$, even if the layer of electrolyte is considerably thicker than the length of wire which is to be etched, typically 1-2 $\mathrm{mm}$. However, the gas bubbles formed during etching partly screens the upper part of the tip and thus reduces the effective length of etching. A stainless steel ball is placed between $\mathrm{M}$ and the sample holder $\mathrm{S}$ to avoid torque transfer when $\mathrm{M}$

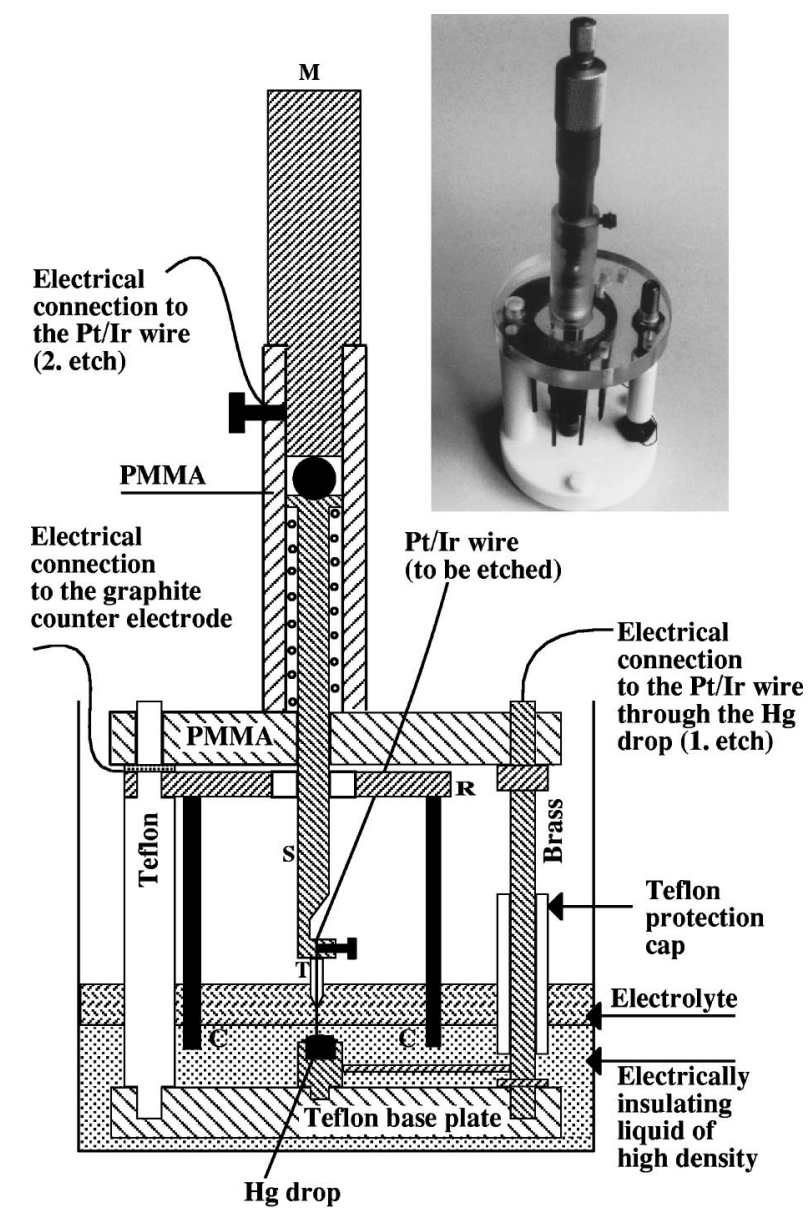

$50 \mathbf{~ m m}$

FIG. 1. Etching setup used in our experiments. In the coarse first etching the applied current passes through the conductive mercury drop in the insulating bottom liquid to the $\mathrm{Pt} / \mathrm{Ir}$ wire. In the finer second etching the current is led to the $\mathrm{Pt} / \mathrm{Ir}$ electrode directly from the micrometer screw marked M. Only the hatched or filled parts of the setup are electrically conductive. $\mathrm{C}$ is the graphite counter electrode while $\mathrm{S}$ is the wire holder.

is adjusted, and a spring ensures firm mechanical and electrical contact.

A continuous $50 \mathrm{~Hz}$ alternating current (ac) voltage of amplitude $\sim 4.3 \mathrm{~V}[3 \mathrm{~V}$ root-mean-square (rms)] is used in the first, coarse etching where the electric current is led to the $\mathrm{Pt} / \mathrm{Ir}$ electrode through the mercury drop, Fig. 1. This first etching is terminated automatically when the lower part of the Pt/Ir wire drops off and thereby almost instantaneously breaks the electrical circuit. Now the upper part of the etching equipment with the sample holder may be dismounted, so that the brass screw fixing the $\mathrm{Pt} / \mathrm{Ir}$ wire to $\mathrm{S}$ can be loosened, and a suitable length of the wire with the coarsely etched tip can be cut off from the rest of the wire. Such tips are stored in a tip holder (or mounted on magnetic AFM base plates). Now a length of new wire can be fed into the sample holder to make it ready for coarse etching of another tip.

When the required number of coarsely etched tips has been produced the tips can again be mounted one by one in the specimen holder $\mathrm{S}$ for sharpening by second (fine) etching. This is performed in the same apparatus as used for the first coarse etching. The setup used for the second etching is 
almost the same as in the first etch, but the teflon shield around the Pt/Ir wire is not needed, and the coarsely etched tip has to be submerged only about $0.5 \mathrm{~mm}$ into the electrolyte layer which remains as in the first etching. The external power supply has to be disconnected from the Hg drop, which is now left isolated in the electrically insulating liquid, and it is instead connected to the Pt/Ir tip via the micrometer screw $\mathrm{M}$. Thus, the current runs via $\mathrm{M}$, the steel ball and the tip holder $\mathrm{S}$ to the tip and then via the electrolyte and the carbon counter electrode $\mathrm{C}$ back to the power supply, Fig. 1. Again $50 \mathrm{~Hz}$ voltage of amplitude $\sim 4.3 \mathrm{~V}(3 \mathrm{~V} \mathrm{rms})$ is applied to the tip, but now only as a specified number of current pulses, each of specified pulse duration and stop phase. The stop phase is continuously adjustable by means of the home built power supply. In the present experiments the stop phase of the pulses was either $+90^{\circ}$ (i.e., the pulse stopped at maximum positive voltage applied to the $\mathrm{Pt} / \mathrm{Ir}$ wire) or $-90^{\circ}$ (i.e., the pulse stopped at maximum negative voltage applied to the $\mathrm{Pt} / \mathrm{Ir}$ wire). The duration of a pulse is specified by the number of full cycles before the truncated stop cycle emerge. We have chosen to use three different numbers of full cycles, namely 0 full cycles (i.e., the actual pulse duration equals the duration of the truncated termination cycle), 5 full cycles (actual pulse duration is equal to $100 \mathrm{~ms}+$ the duration of the truncated cycle), or 50 full cycles (actual pulse duration is equal to $1000 \mathrm{~ms}$ plus the duration of the truncated cycle).

The correct tip submersion in the electrolyte layer is obtained by applying a low voltage before tip-electrolyte contact is established, and when operation of the micrometer screw makes the current start the screw is turned down another $0.5 \mathrm{~mm}$.

The insulating liquid used is methyl trichloro acetate $\left(\mathrm{CCl}_{3} \mathrm{COOCH}_{3}\right)$, which is less poisonous than carbon tetrachloride $\left(\mathrm{CCl}_{4}\right)$ previously used in the setup by Song et al. The electrolyte is made of $20 \mathrm{ml}$ saturated $\mathrm{CaCl}_{2}$ solution $\left(\rho=1.44 \mathrm{~g} / \mathrm{cm}^{3}\right)$ and $20 \mathrm{ml} 3.3 \mathrm{wt}$. \% $\mathrm{HCl}$ with $2 \mathrm{ml}$ acetone added (i.e., $\sim 5 \%$ by volume). This gives a layer thickness of the electrolyte of about $4-5 \mathrm{~mm}$ in our current etching setup. The electrolyte can typically be used for three to six coarse etchings before it has to be exchanged (or to be refilled with acetone). The acetone is added to control the gas bubble formation at the electrode. If no acetone was added the bubbles formed during etching grew very large before they detached from the electrode, and they gave rise to inhomogeneous etching of the tip. The addition of acetone makes the bubbles escape from the electrode already at sizes lower than $0.1 \mathrm{~mm}$ thereby making the etching process more smooth. ${ }^{8}$ If notably more than $5 \%$ acetone by volume is used, the content of acetone becomes too high, and a two-phase solution emerges with pure acetone on top. Furthermore, acetone is soluble in the methyl trichloro acetate (as well as in carbon tetrachloride) used as insulating bottom liquid. In order to avoid it being too diluted by acetone, the concentration of acetone in the electrolyte must be kept as low as possible without losing the effect of letting small bubbles escape the electrodes. We have found that a concentration of $5 \%$ by volume of acetone fulfills both requirements.

The main differences between the present setup and the setup in Ref. 7 are the introduction of the mercury drop electrode contact and the graphite rod counter electrode. Song et al. used a platinum foil to establish electrical contact to the $\mathrm{Pt} / \mathrm{Ir}$ wire in the insulating bottom liquid. The advantages of the mercury drop setup are that the sideways force on the $\mathrm{Pt} / \mathrm{Ir}$ wire occurring in the setup with the platinum foil is eliminated, thus lowering the risk of bending the $\mathrm{Pt} / \mathrm{Ir}$ wire during etching and a better electrical contact is achieved. The disadvantage of the mercury drop setup is that the surface tension of the mercury drop has to be overcome by the Pt/Ir wire for a satisfactory electrical contact to be established. This is in general no problem with a fresh and unetched Pt/Ir wire of diameter $0.25 \mathrm{~mm}$. However, if for some reason it is wanted to check the etching before it has come to an end, the surface tension may become a problem in the subsequent reinstallation of the $\mathrm{Pt} / \mathrm{Ir}$ wire in the etching setup, because the etched part of the wire may be too thin to resist the upwards force exerted by the mercury drop before the wire penetrates the surface of the drop. Usually there is no reason for checking the Pt/Ir wire before the coarse etching is finished, and therefore the surface tension of the drop does not present a serious problem.

Another problem might be the amalgamation of that part of the Pt/Ir wire which is submerged into the mercury drop. Earlier studies ${ }^{18}$ shed light on the solubility of mercury in platinum. In these, highly purified platinum powder $(0.2-0.3$ g) was mixed with mercury in a quartz tube that subsequently was evacuated and heated to a given temperature for up to $350 \mathrm{~h}$. The lattice parameter of the platinum was measured by $\mathrm{x}$ rays before and after the treatment, and if it was changed less than $0.001 \AA$, the solubility of mercury was estimated to be negligible. This turned out to be the case for temperatures below $100{ }^{\circ} \mathrm{C},{ }^{18}$ implying that the solubility of mercury in platinum is negligible for temperatures below $100^{\circ} \mathrm{C}$. In our experiments, the temperature of the mercury drop was close to room temperature, so amalgamation of the $\mathrm{Pt} / \mathrm{Ir}$ wire appears not to be a serious problem. It should be noted that the solubility of mercury in platinum increases abruptly at a temperature around $250^{\circ} \mathrm{C}$ due to reactions in the $\mathrm{Pt}-\mathrm{Hg}$ system, ${ }^{18}$ reaching a value of 15.3 at. \% at a temperature of $255^{\circ} \mathrm{C}$. Three different intermediate solid phases have been identified, ${ }^{19,20}$ namely the $\mathrm{Hg}_{4} \mathrm{Pt}$ phase, the $\mathrm{Hg}_{2} \mathrm{Pt}$ phase, and the $\mathrm{HgPt}$ phase. Due to the low degree of reaction between the $\mathrm{Pt} / \mathrm{Ir}$ wire and the $\mathrm{Hg}$ drop the drop does not need cleaning before at least ten coarse etchings have been performed. ( $\mathrm{Hg}$ can be recovered from the amalgame by treatment with $\mathrm{HNO}_{3}$ ).

Finally, it should be mentioned that generally the dropoff part of the Pt/Ir wire cannot be used as a STM tip simply because it is too difficult to find it undamaged in the mercury drop. This may be the most serious disadvantage compared to the setup in Ref. 7.

The graphite counter electrode used instead of the annular platinum wire counter electrode in Ref. 7 ensures that this electrode is not etched and its open structure allows circulation of the electrolyte in all the layers. 


\section{PtIr tip \#15}

\section{Before second etching}
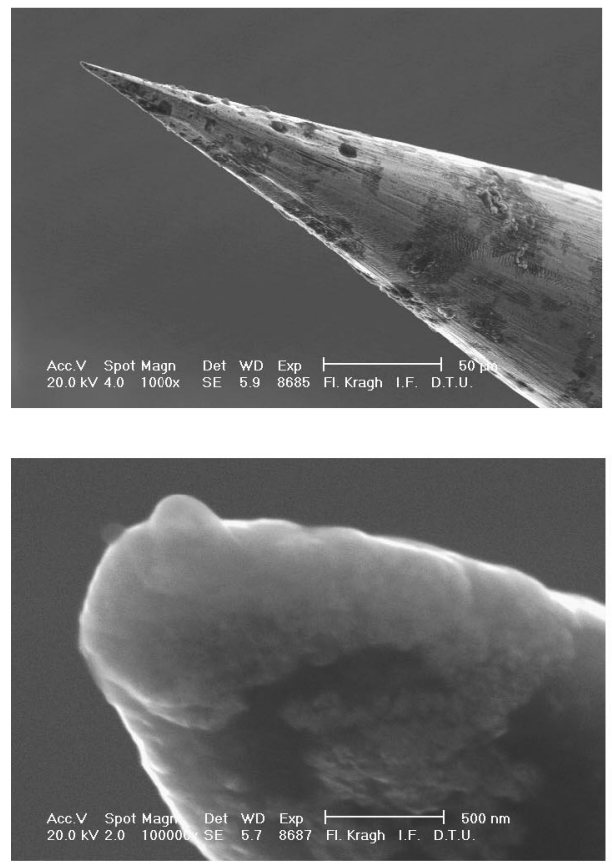

After second etching
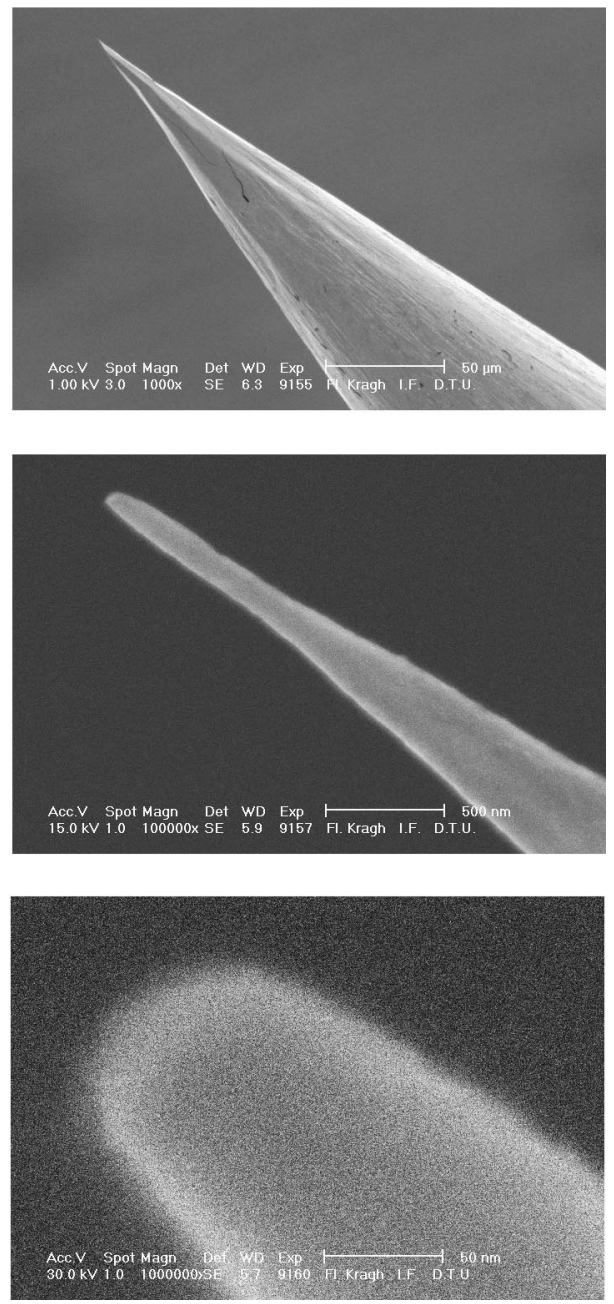

FIG. 2. Scanning electron micrographs of tip PtIr \#15. It is observed that the tip is sharpened significantly by being second etched. The scale bars shown are $50 \mu \mathrm{m}$ in the upper row, $500 \mathrm{~nm}$ in the middle row and $50 \mathrm{~nm}$ in the lower row.

\section{B. Etching process}

The etching of a $\mathrm{Pt} / \mathrm{Ir}$ wire is a rather lengthy process due to platinum being a noble metal. In a review paper by Llopis $^{21}$ it is stated that anodic corrosion of platinum in $\mathrm{H}_{2} \mathrm{SO}_{4}$ or in $\mathrm{NaOH}$ is almost undetectable while some corrosion of platinum is observed in a solution containing $\mathrm{Cl}^{-}$ ions as long as the potential across the electrochemical cell is lower than $0.91 \mathrm{~V}$. The solved platinum atoms form either a $\mathrm{Pt}(\mathrm{II}) \mathrm{C}_{4}^{2-}$ complex or a $\mathrm{Pt}(\mathrm{IV}) \mathrm{C}_{6}^{2-}$ complex. These products compete with the chloride ion, $\mathrm{Cl}^{-}$, in reaching the platinum electrode when it is the anode in the electrochemical cell, thus lowering the attacks by the chloride ions on the platinum surface atoms. When the voltage applied to the cell exceeds $1 \mathrm{~V}$ the electrochemical yield for anodic corrosion decreases to nearly zero due to passivation of the electrode. This passivation is mainly a result of formation of a molecular oxide layer on the platinum surface ${ }^{21}$ but may also be influenced by the attraction of the negatively charged complexes $\mathrm{PtCl}_{4}^{2-}$ and $\mathrm{PtCl}_{6}^{2-}$ to the anode thus preventing the chloride ions $\mathrm{Cl}^{-}$from reaching the anode.

Superposing an ac current on the direct current (dc) current in the electrochemical cell markedly enhances the cor- rosion rate of the platinum. ${ }^{21}$ This occurs when the current density $i_{\mathrm{ac}}$ of the ac current at the platinum electrode surface exceeds a critical value $i_{\text {ac,crit }}$ which is proportional to the dc current density $i_{\mathrm{dc}}$. The alternating current reverts the passivation mechanisms in the negative phase (the oxide layer on the platinum electrode is dissolved when the electrode is the cathode in the cell), thereby leaving a "fresh" platinum electrode in the positive phase. Finally, it is mentioned by Llopis that the etching rate of platinum increases for decreasing frequency, becoming intense when a $10 \mathrm{~Hz}$ square-wave alternating current is applied to the electrochemical cell.

In order to compare our etching rates with the ones cited by Llopis in (Ref. 21) we assume that the shape of the platinum electrode before etching is a cylinder of length $l$ and radius $r_{0}(=0.125 \mathrm{~mm})$, while after etching the shape has turned into two opposing cones with the total height $l$ and a base radius $r_{0}$. This gives a corrosion rate $\delta^{*}$ of 0.89 $\mathrm{mg} /\left(\mathrm{mm}^{2} \mathrm{~h}\right)$ in our experiment at an ac current density $i_{\mathrm{ac}}$ of $63.3 \mathrm{~mA} / \mathrm{mm}^{2}$ (based on the initial cylinder surface area) ${ }^{22}$ giving an electrochemical yield of $0.4 \%$ for Pt(II) and $0.8 \%$ for Pt(IV). In Ref. 21 the reported etching rates are found experimentally only for ac current densities up to 0.18 


\section{PtIr tip \#17}

Before second etching
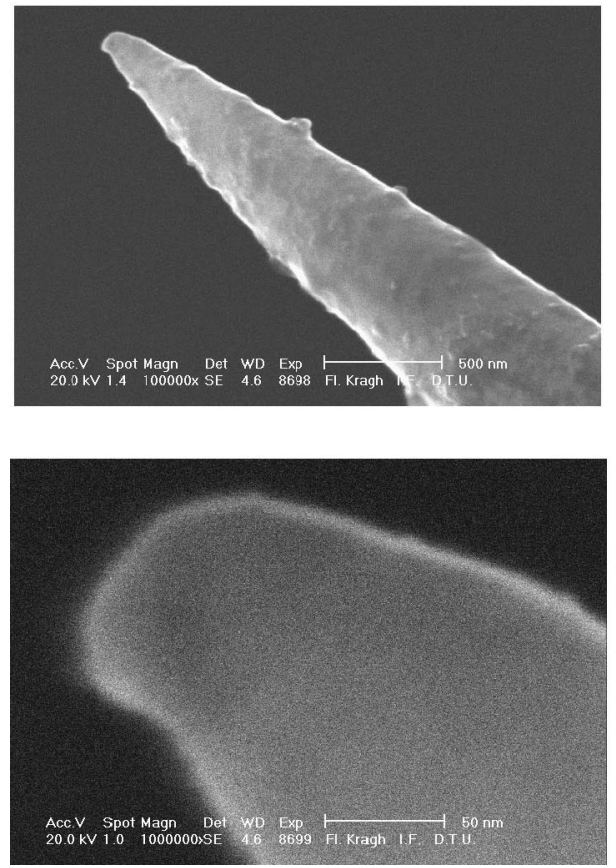

\section{After second etching}
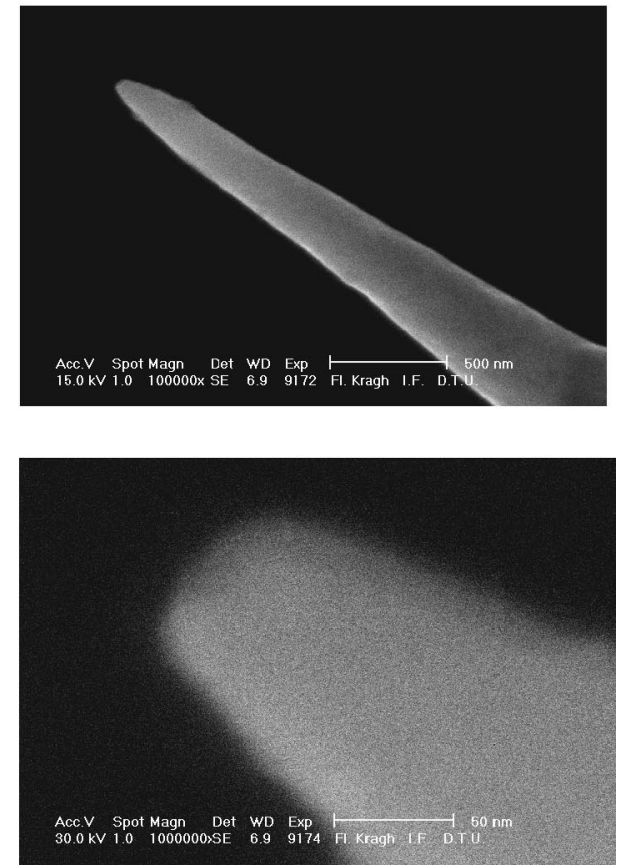

FIG. 3. Scanning electron micrographs of tip PtIr \#17. Already after the first etching this tip was sharp, having a radius of curvature of $\sim 50$ $\mathrm{nm}$. After the second etching the tip radius was as small, maybe even slightly smaller than before. The scale bars shown are $500 \mathrm{~nm}$ in the upper row and $50 \mathrm{~nm}$ in the lower row.
$\mathrm{mA} / \mathrm{mm}^{2}$, and for dc current densities of $0.00,0.05,0.5,2.5$, $5.0 \mu \mathrm{A} / \mathrm{mm}^{2}$. Extrapolating the $i_{\mathrm{dc}}=0 \mu \mathrm{A} / \mathrm{mm}^{2}$ data to an ac current density of $63.3 \mathrm{~mA} / \mathrm{mm}^{2}$ leads to a corrosion rate $\delta^{*}=0.49 \mathrm{mg} /\left(\mathrm{mm}^{2} \mathrm{~h}\right)$, i.e., $55 \%$ of our estimated experimental value. ${ }^{23}$ The molar concentration of the $\mathrm{Cl}^{-}$ions was 4 mole/l in the experiment reported on by Llopis ${ }^{21}$ while it was 5.4 mole $/ l$ in our experiment. This difference might partially explain the observed enhanced etching of the platinum wire in our experiments, but an extrapolation of Llopis' data to the extent above may not be justified, because a current density as high as the one used in our experiments requires high potentials, and different reaction channels may occur in different potential regimes. It is known that both oxygen and chloride compete for sites on the platinum electrode surface when it is positive, but for positive potentials lower than circa $1 \mathrm{~V}$, chloride ions win and corrosion takes place while for positive potentials larger than circa $1 \mathrm{~V}$ oxygen starts to chemisorb to the surface leading to the passivation of the electrode surface. ${ }^{21}$ With these facts in mind, it does not seem appropriate to extrapolate Llopis' data to our value of current density, because the current density used in our experiments is obtained for an applied voltage of $3 \mathrm{~V} \mathrm{rms,}$ which is way above the passivation regime. Therefore, it seems necessary to find another etching mechanism which can explain the high etching rate observed in our experiments.

A suggestion for another etching mechanism besides anodic corrosion (which is based on the attachment of the chloride ions $\mathrm{Cl}^{-}$to the platinum anode followed by detachment of the complexes $\mathrm{PtCl}_{4}^{2-}$ or $\mathrm{PtCl}_{6}^{2-}$ when the anodic potential is high enough) would be "'microexplosions." This idea, brought about by Andersen, ${ }^{24}$ is based on the fact that the potential applied to the electrochemical cell is above the dis- sociation potential of water $(1.23 \mathrm{~V})^{25}$ leading to the formation of oxygen at the anode and hydrogen at the cathode. Thus hydrogen will be formed at the platinum electrode when it is negative, and some of the hydrogen formed will diffuse interstitially into the electrode. In the positive phase oxygen will be formed, and now some of it will diffuse into the platinum, though the penetration depth is likely to be shorter for oxygen. ${ }^{26}$ Despite the differences in penetration depths for hydrogen and oxygen, a reactive mixture of hydrogen and oxygen will be formed in the outer layers of the platinum electrode, leading to microexplosions when this gas mixture reacts chemically. ${ }^{28}$ Scanning electron microscopy pictures shown in Fig. 6 may support this scenario.

\section{RESULTS AND DISCUSSION}

\section{A. Tip etching}

Figure 2 presents five scanning electron micrographs of the Pt/Ir tip called PtIr \#15. It was coarse etched in an old setup without a contact in the insulating bottom liquid, implying that the etching current was supplied through the upper part of the $\mathrm{Pt} / \mathrm{Ir}$ wire during both first and second etchings. In cases like this, the etch operator has to manually switch off the current when the lower part of the wire drops off in order to terminate the etching. Unfortunately, the current was switched off too late, leaving a very blunt tip. This is seen in the left hand column of Fig. 2. However, second etching of this tip in the same electrolyte using pulses sharpens the tip as shown in the right hand column.

As mentioned above, the second etching was performed by means of $50 \mathrm{~Hz}$ ac pulses of specified duration and stop phase [amplitude $\sim 4.3 \mathrm{~V}(3 \mathrm{~V} \mathrm{rms})$ ]. An electronic equipment especially developed for that purpose was used ${ }^{7}$ (de- 

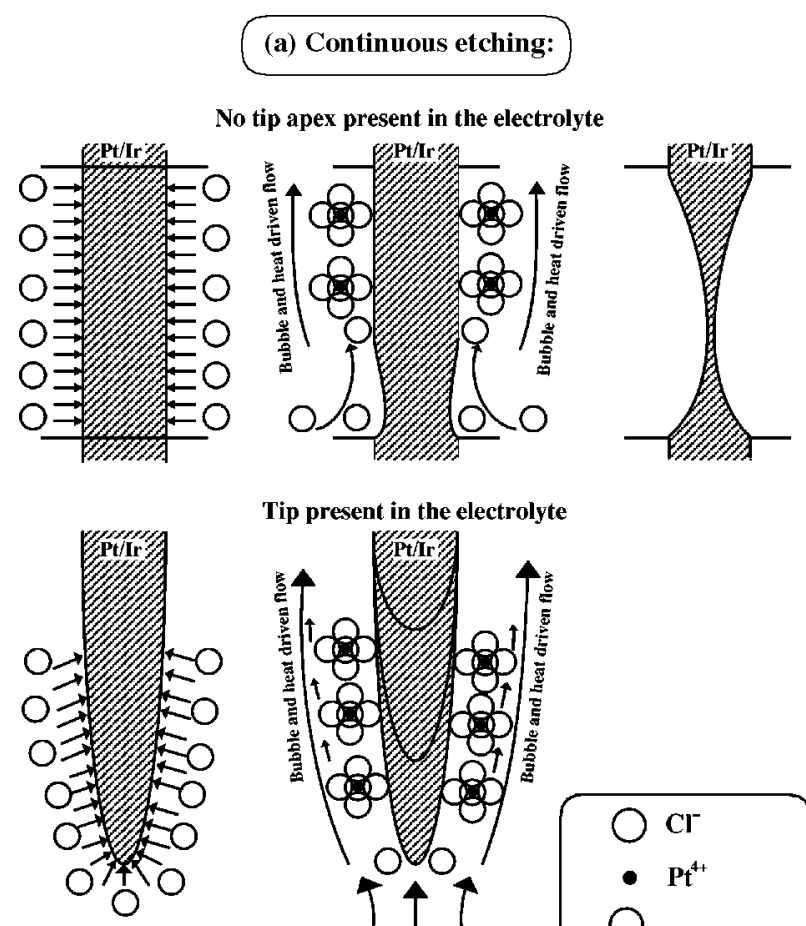

Tip present in the electrolyte
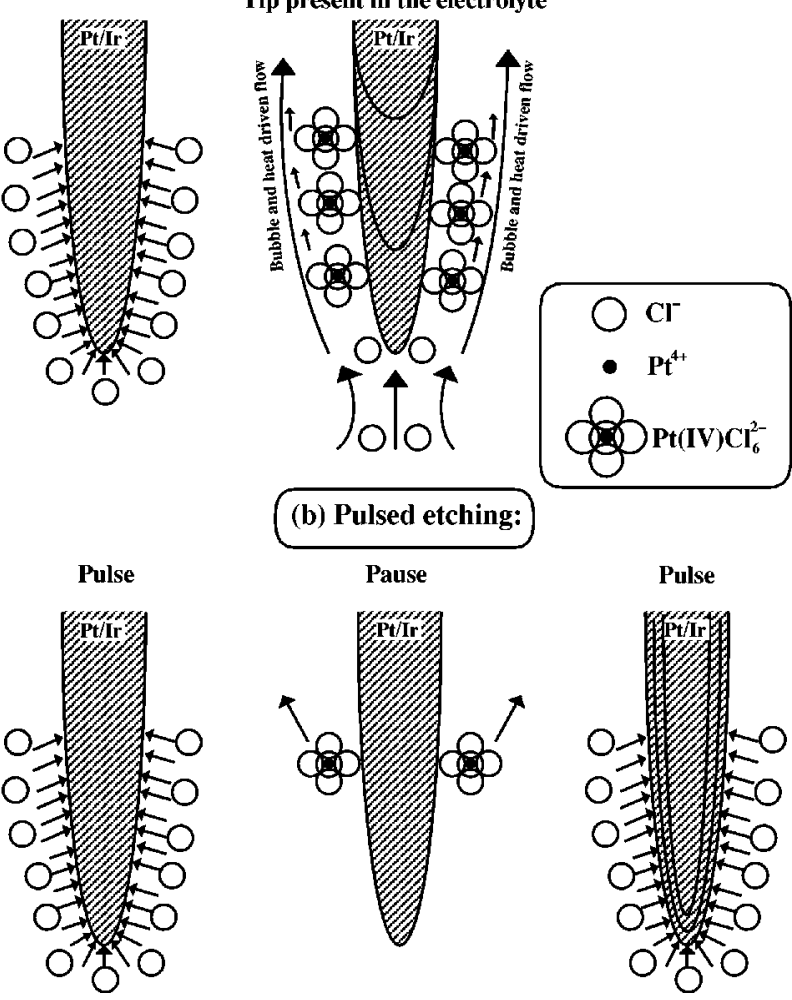

FIG. 4. Important differences between continuous etching that is used in the coarse first etching, and the pulsed etching used in the finer second etching, are illustrated. By using pulsed etching tip shank etching occurs along with the tip apex etching because bubbles and platinum complexes are removed in the pauses. This prevents the formation of a blunt tip. If no tip apex is present, the resulting tip shank shape by continuous etching is as exemplified in the upper row to the right, the ultimate shape being dependent on the intensity of bubble formation and its shielding effect.

tailed information of this equipment is available from the authors). The stop phase was deliberately chosen to be either $+90^{\circ}$ or $-90^{\circ}$ (i.e., the pulse stopped when it was either most positive or most negative), while the duration of the pulses was changed between $\sim 10$ and $\sim 1000 \mathrm{~ms}$. It turned out that the stop phase is not important when etching $\mathrm{Pt} / \mathrm{Ir}$ wires, contrary to etching tungsten wires. In the latter case, the stop phase had to be negative in order to get rid of the oxide layer. ${ }^{7}$ The reason for the insensitivity to the stop phase in the case of platinum is probably that platinum is an inert metal, and therefore the etching times are long (in comparison with, e.g., tungsten), rendering the last 10-20 ms insignificant. The second etching process is a combined etching/cleaning process. In the case of tip PtIr \#15, the radius of curvature was substantially reduced by the second etching made by 40 pulses, each of duration $1 \mathrm{~s}$ and with one pulse every 2 nd second.

The second etching procedure outlined above for tip PtIr \#15 (i.e., forty polishing pulses, each of duration $1 \mathrm{~s}$ ) can be used also on tips which are already sharp after the first etching, as the tip PtIr \#17 presented in Fig. 3. This tip got a small radius of curvature already by the coarse first etching for which reason a second etching would not be necessary. However, in order to establish whether or not a second etching performed routinely on all etched tips would destroy tips already sharp from the first etching, several tips, which all had a small radius of curvature after the first etching, were second etched using the same scheme as for tip PtIr \#15. Actually, the tip PtIr \#17 got 60 pulses, each of duration 1, while PtIr \#15 got only 40. Even 60 pulses do not seem to increase the radius of curvature of the tip if it is sharp already.

It is not easy to explain why the tip radius of curvature of an already sharp tip apparently stays unchanged during a second etching. In Ref. 7 it is suggested that the second etching of the tungsten wire occurs only at the tip shanks while the tip apex is protected from being etched by a space charge distribution of inactive (with respect to etching) ions surrounding the apex due to the higher electric field strength found at the apex. If the shank is etched while the apex is not, a higher aspect ratio tip and thus a smaller radius of curvature of the tip apex is achieved.

In the present case, the active component in etching platinum is the chloride ion $\mathrm{Cl}^{-}$forming the platinum complexes $\mathrm{Pt}(\mathrm{II}) \mathrm{C}_{4}^{2-}$ or $\mathrm{Pt}(\mathrm{IV}) \mathrm{C}_{6}^{2-}$ which are inactive from an etching point of view. These complexes may compete with the chloride ions for the free sites on the surface of the platinum electrode, but it does not seem evident that these complexes are better to force out the chloride ions at the tip apex than at the tip shank. Furthermore, according to our discussion above, the $\mathrm{Cl}^{-}$ion-induced corrosion may be the minor contribution to the total etching. Therefore, the etching scenario suggested in Ref. 7 does not seem to apply in the case of platinum.

Taking the microexplosion scenario as our starting point it may be argued that at the tip apex the lattice will be expanded more than anywhere else because here the electric field is strongest and the restoring lattice forces are smallest. This lattice expansion will most likely change the hydrogen as well as the oxygen content in the lattice, but whether the densities will increase or decrease is not evident. This must depend on how the interstitial diffusion of the hydrogen and oxygen atoms changes with changing lattice parameter in the host matrix.

The striking improvement of tip PtIr \#15 during second etching, see Fig. 2, must in some way depend on the nature of the process, that is the shift between etching for $1 \mathrm{~s}$ and having a pause for at least $1 \mathrm{~s}$. If instead the etching had been performed by one single continuous $50 \mathrm{~Hz}$ ac pulse of $40 \mathrm{~s}$ duration the tip would most likely have stayed blunt just as if the first etching had lasted $40 \mathrm{~s}$ more (the etching time of tip PtIr \#15 in the first etching was $1 \mathrm{~h}$ and $40 \mathrm{~min}$ ). Therefore, it seems of fundamental importance that second etching is performed with ac pulses separated by pauses, which are at 


\section{PtIr tip \#06}

\section{Before second etching}
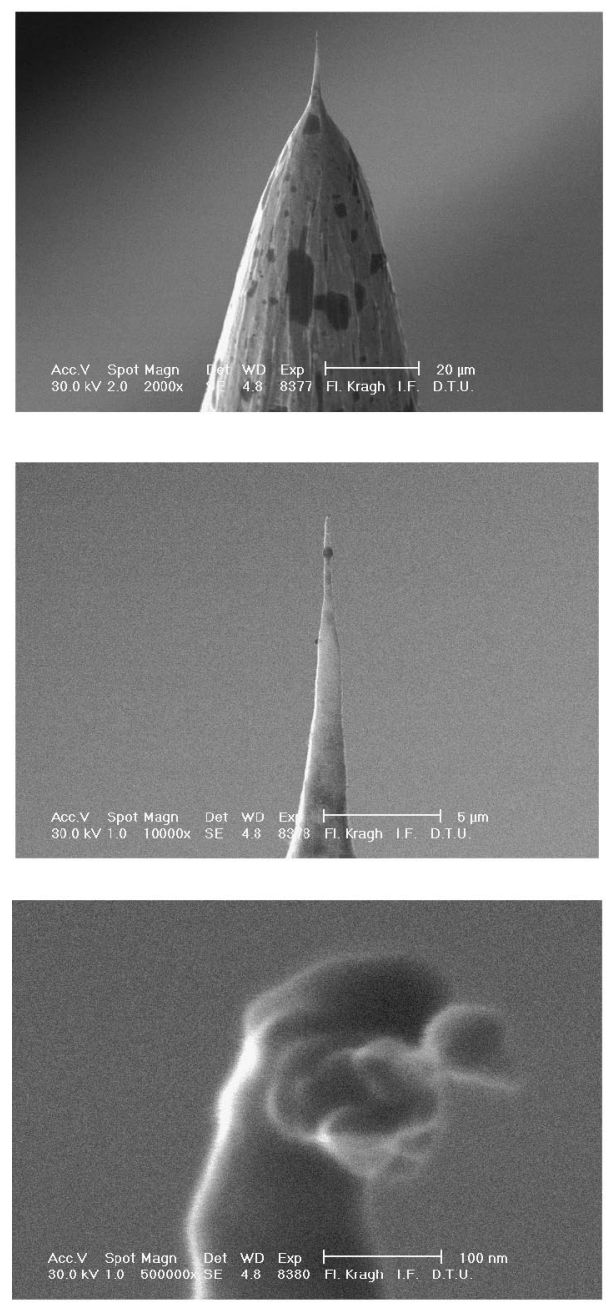

\section{After second etching}
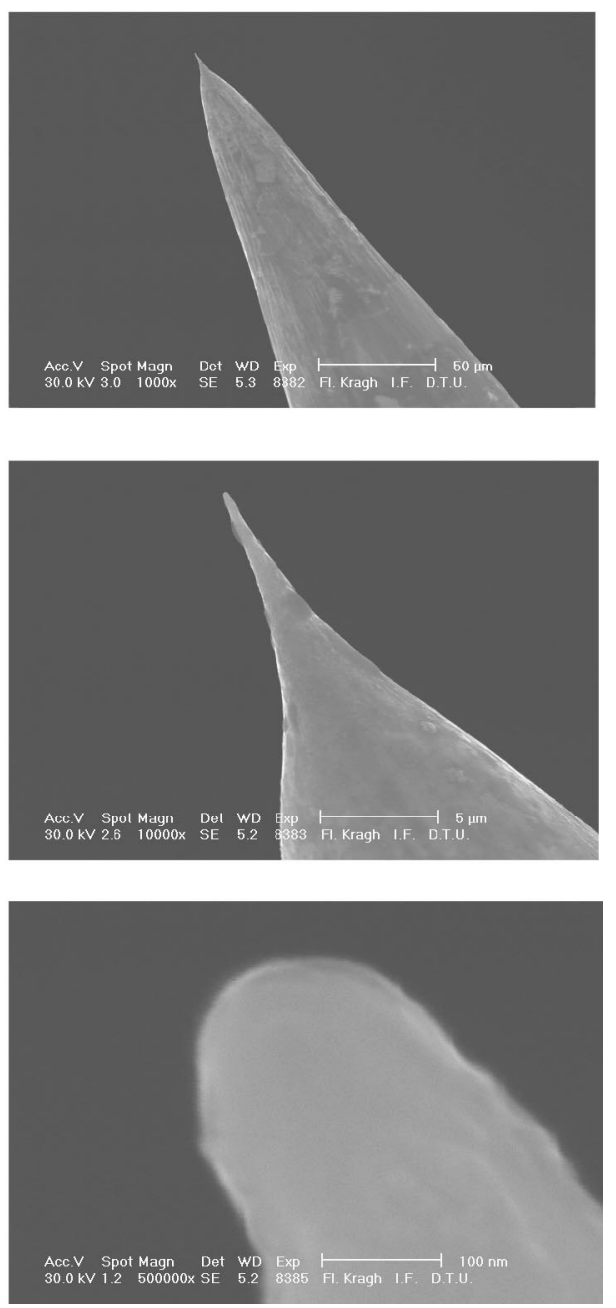

FIG. 5. Scanning electron micrographs of tip PtIr \#06. As in the case of tip PtIr \#17, the small radius of curvature is almost maintained after the second etching. However, the tip shank is only half as long as after the first etching. The scale bars used are 20 and $50 \mu \mathrm{m}$ in the top row (left and right hand micrographs, respectively), $5 \mu \mathrm{m}$ in the middle row, and $100 \mathrm{~nm}$ in the lower row. least as long as the etching pulses. Furthermore, the pulse duration and the pause duration must both be comparable to some characteristic time in the ion diffusion caused by the electric field and the convection of electrolyte due to bubble and heat formation, see Fig. 4. When the etching is initiated fresh electrolyte everywhere at the tip surface results in an even etch rate at the tip shank and the tip apex. During etching the platinum/chloride complexes $\mathrm{Pt}(\mathrm{II}) \mathrm{Cl}_{4}^{2-}$ and $\mathrm{Pt}(\mathrm{IV}) \mathrm{Cl}_{6}^{2-}$ as well as bubbles move upwards along the shank while fresh electrolyte arrives at the tip apex and gradually the etching of the shank is inhibited. This occurs during continuous etching and gives rise to a blunt tip if its apex is exposed to the electrolyte. If no tip apex is present, which will be the case during the coarse first etching, the shape of the tip shank typically obtained before the lower part breaks off and thereby terminates the first etching will be as shown to the right in the upper row of Fig. 4.

If a pause is introduced, as shown in Fig. 4(b) the layer of complexes and bubbles dissolves and moves upwards during the pause and fresh electrolyte can attack the shank during the subsequent etching pulse. The etching rates of the tip shank and the tip apex will then be comparable thus preventing the formation of a blunt tip. We believe that this is a reasonable picture of the etching process. The duration of the pulses and the pauses is decisive for the buildup and the subsequent disappearance of complexes and bubbles in the electrolyte as well as for the hydrogen and oxygen content in the surface layers of the tip. In other words, the pulse and pause durations are important parameters which can be used to change the relative etching rates of shank and apex etching and thereby tailor a tip shank shape with a particular aspect ratio.

According to the above-mentioned etching scenario both tip apex etching and tip shank etching occurs during second etching of Pt/Ir tips. Figure 2 shows a pronounced sharpening of a blunt tip by second etching while Fig. 3 shows how an already sharp tip remains sharp during second etching. Figure 5 reveals that the second etching removes the front of the tip. In this case the radius of curvature after the second etching is slightly larger than usual and exceeds that of the first etching, though it is still fairly small.

Tip PtIr \#06 shown in Fig. 5 has a characteristic shape with a sudden narrowing of the wire into a smaller microtip protruding from a "neck" at the tip shaft. This is fairly atypical. Out of 12 tips investigated in the scanning electron microscope only this one, and tips which are first etched at 


\section{PtIr tip \#22}

Before second etching
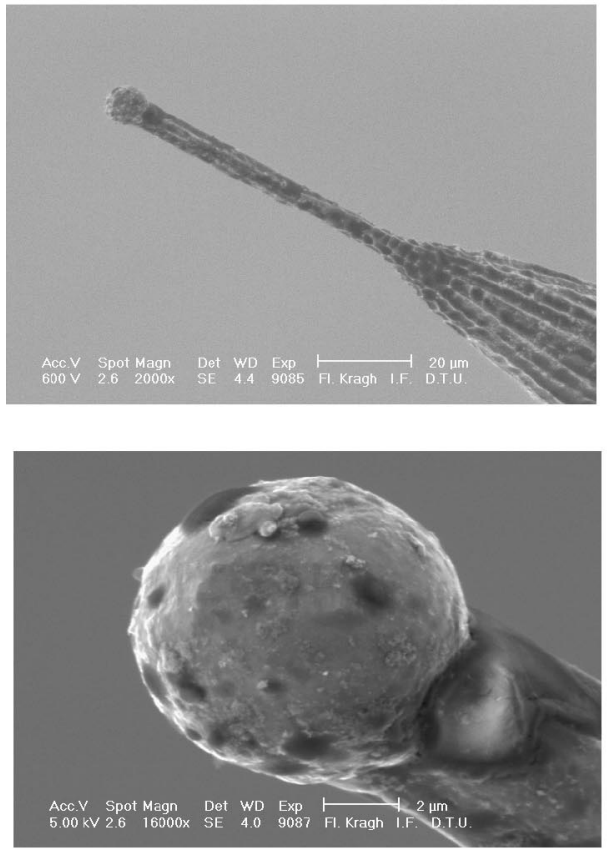

After second etching
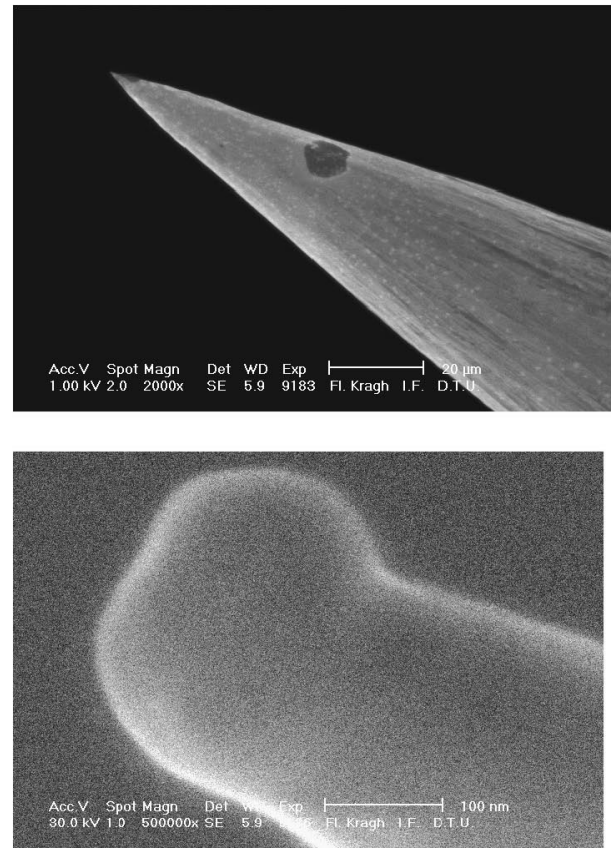

FIG. 6. Scanning electron micrographs of tip PtIr \#22. The current density in the first etching was twice as high as usual, i.e., $\sim 120 \mathrm{~mA} / \mathrm{mm}^{2}$. Four tips were etched with this high current density, all showing the features apparent from these pictures of tip PtIr \#22, namely the very rough surface covered with "craters," the huge sphere which terminates the tip, and the neck formation also seen for tip PtIr \#06, Fig. 5. The scale bars in the upper row are both $20 \mu \mathrm{m}$ while in the lower row the scale bars are $2 \mu \mathrm{m}$ and $100 \mathrm{~nm}$ in the left hand and the right hand micrographs, respectively. twice as high current density as usual, exhibited this microtip formation. The rest of the tips investigated by scanning electron microscopy look as the tips PtIr \#15 and \#17 (Figs. 2 and 3).

The current density is a very important parameter in the etching process. The etching time depends heavily on the current density, and decreases with increasing current density. However, the operator should not simply turn up the voltage and thereby the current to get shorter etching times. Usually this leads to a very rough surface, as shown in Fig. 6. The rough surface may be a result of increased explosive activity. For tip PtIr \#22 the current density was twice as high as usual leading to higher production rates of oxygen and hydrogen in the positive and negative phases, respectively. Therefore, the amounts of stored hydrogen and oxygen in the platinum lattice as well as their penetration depths will increase which leads to more and deeper microexplosions. For time intervals in which the applied potential is below the dissociation potential of water, the corrosion process, in which the platinum-chloride complexes are formed, works as a polishing process, smoothing out the craters left after the explosions. The combined effect of microexplosions and corrosion (or polishing) may lead to a surface which looks like the one shown in Fig. 6.

It should be noted that the wire material used is $90 \%$ platinum and $10 \%$ iridium. At $600{ }^{\circ} \mathrm{C}$ the maximum solubility of iridium in platinum is below 6 at. $\%$ iridium. ${ }^{20}$ Therefore, at thermodynamic equilibrium the iridium atoms in the $\mathrm{Pt} / \mathrm{Ir}(10 \%)$ wire will precipitate and form inclusions with a semicoherent interface in the platinum matrix. However, we have reason to believe that the wire material is not at thermodynamic equilibrium. X-ray measurements on the wire material revealed a lattice constant of $4.088 \AA$, ${ }^{30}$ while the lattice constant of a pure platinum wire was found to be
$3.904 \AA$ (Ref. 30) using the same method of X-ray scattering. The tabulated value of the lattice constant of pure platinum is $3.9231 \pm 0.0005 \AA,{ }^{25}$ while it is $3.83 \AA$ for pure iridium. ${ }^{31}$ If the iridium in the $\mathrm{Pt} / \mathrm{Ir}(10 \%)$ wire had formed precipitates in the platinum matrix, two lattice constants would have been found, one for pure iridium and one for (almost) pure platinum, but only one lattice parameter was found, and it was bigger than those of both pure platinum and pure iridium. It is not obvious why the lattice parameter should be bigger for a homogeneous alloy of platinum and iridium, but the important part is that no rings were found corresponding to the lattice parameters of pure iridium or pure platinum. Thus, we do not believe the iridium in the wire has precipitated. Accordingly, the etching of the Pt/Ir $(10 \%)$ wire should be homogeneous and no indication exists that the craters found in the etched surface of tip PtIr \#22 could be due to iridium inclusions being etched away before the surrounding platinum is etched away.

In Fig. 6 another feature characteristic of first etching at high current density is shown, namely the formation of a " "huge"' sphere at the end of the tip shaft. During etching, the bridge between the upper half and the lower half of the platinum/iridium wire exposed to the electrolyte becomes thinner and thinner, and eventually it breaks, which terminates the first etching. The etching current runs through this bridge, and with the thinning of the bridge the current density through it increases. We believe that eventually the current density through the cross section of the bridge becomes so large that the bridge simply melts, thereby forming the huge sphere of wire material. The formation of the sphere has been observed for all tips etched at high current densities $\left(\sim 120 \mathrm{~mA} / \mathrm{mm}^{2}\right)$. 

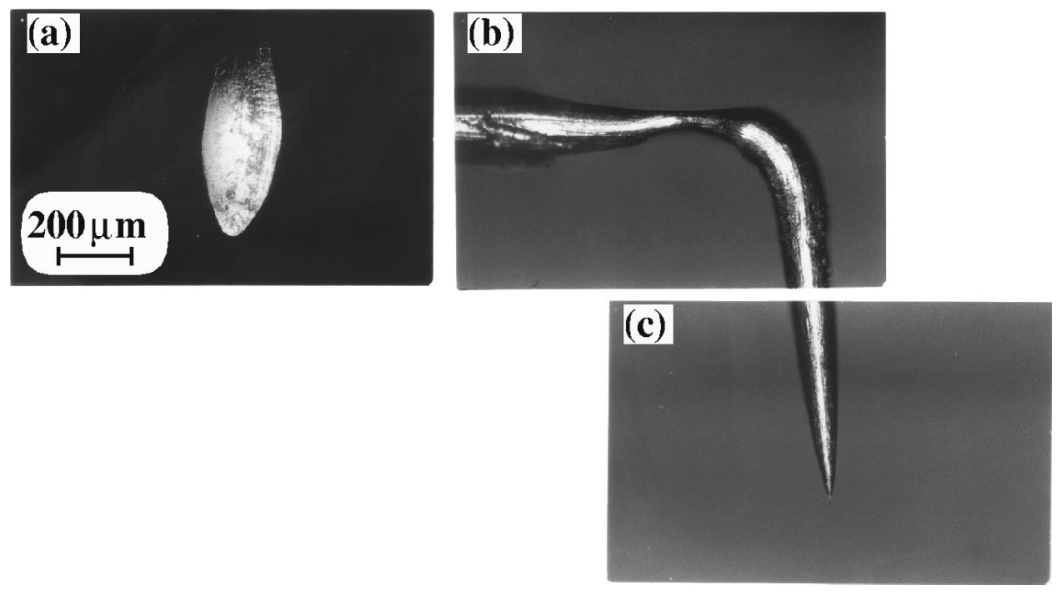

FIG. 7. Three pictures of tip PtIr \#21 taken in an optical microscope after the tip was bent and a concave mirror was made on the upper side of the cantilever. The scale bar shown in (a) applies to all three pictures. In (a) the cantilever is seen from above, revealing the concave mirror, while (b) shows the cantilever/tip system in side view with the concave mirror at the upper side. Picture (c) was taken to check that the tip was not harmed during the bending and mirror formation processes.

\section{B. Tip bending}

In order to produce tips for AFM and SEFM for use in our atomic force microscope the etched tips were bent at an angle of $90^{\circ}$ some hundreds of micrometers away from the tip apex, thereby forming an integrated tip/cantilever system, see Figs. 7(b) and 7(c). ${ }^{32}$ The etched tip was mounted on a magnetic base plate used in our AFM. This unit was then positioned and fixed in a special tool so that the tip shank could be bent by a slider attacking perpendicular to the tip shaft about one wire diameter outside the support edge of the tool. On top of the cantilever a concave mirror was then created by pressing a ball of stainless steel, diameter $3.2 \mathrm{~mm}$, into the cantilever by applying a force of $100-150 \mathrm{~N}$, thus exceeding the tensile strength of Pt90/Ir10 over a suitable area. The ball is mounted in a pressing tool which can replace the bending tool with the slider. The resultant cantilever is shown from above in Fig. 7(a) and in side view in Figs. 7(b) and 7(c). These tips were successfully used for tapping mode AFM as well as for measurements of electrostatic forces. ${ }^{32}$

\section{ACKNOWLEDGMENTS}

The authors are very grateful to Dr. Jens E. T. Andersen from the Department of Chemistry, DTU, for discussions on the electrochemical etching processes and to Flemming Kragh for his thorough work at the scanning electron microscope at our department. This work has been supported by the Danish Ministries of Industry and Research in the framework of Center for Nanostructures (CNAST).

${ }^{1}$ A. A. Gewirth, D. H. Craston, and A. J. Bard, J. Electroanal. Chem. 261, 477 (1989).

${ }^{2}$ J. Garnæs, F. Kragh, K. A. Mørch, and A. R. Thölén, J. Vac. Sci. Technol. A 8, 441 (1990).

${ }^{3}$ I. H. Musselman and P. E. Russell, J. Vac. Sci. Technol. A 8, 3558 (1990).

${ }^{4}$ A. J. Melmed, J. Vac. Sci. Technol. B 9, 601 (1991).

${ }^{5}$ M. Fotino, Rev. Sci. Instrum. 64, 159 (1993).

${ }^{6}$ L. A. Hockett and S. E. Creager, Rev. Sci. Instrum. 64, 263 (1993).

${ }^{7}$ J. P. Song, N. H. Pryds, K. Glejbøl, K. A. Mørch, A. R. Thölén, and L. N. Christensen, Rev. Sci. Instrum. 64, 900 (1993).

${ }^{8}$ L. Libioulle, Y. Houbion, and J.-M. Gilles, Rev. Sci. Instrum. 66, 97 (1995).

${ }^{9}$ V. Weinstein, M. Slutzky, A. Arenshtam, and E. Ben-Jacob, Rev. Sci. Instrum. 66, 3075 (1995).
${ }^{10}$ C. Schönenberger and S. F. Alvarado, Phys. Rev. Lett. 65, 3162 (1990).

${ }^{11}$ C. Schönenberger, Phys. Rev. B 45, 3861 (1992).

${ }^{12}$ C. Schönenberger and S. F. Alvarado, Rev. Sci. Instrum. 60, 3131 (1989).

${ }^{13}$ J. E. Stern, B. D. Terris, H. J. Mamin, and D. Rugar, Appl. Phys. Lett. 53, 2717 (1988).

${ }^{14}$ B. D. Terris, J. E. Stern, D. Rugar, and H. J. Mamin, Phys. Rev. Lett. 63, 2669 (1989).

${ }^{15}$ B. D. Terris, J. E. Stern, D. Rugar, and H. J. Mamin, J. Vac. Sci. Technol. A 8, 374 (1990).

${ }^{16}$ S. Watanabe, K. Hane, T. Ohye, M. Ito, and T. Goto, J. Vac. Sci. Technol. B 11, 1774 (1993).

${ }^{17}$ Y. Fukano, T. Uchihashi, T. Okusako, K. Hontani, A. Chayahara, Y. Sugawara, Y. Yamanishi, T. Oasa, T. Okada, and S. Morita, International Conference on Advanced Microelectronic Devices and Processing, p. 365.

${ }^{18}$ A. S. Kertes, in Mercury in Liquids, Compressed Gases, Molten Salts, and Other Elements, Solubility Data Series, edited by H. L. Clever et al. (Pergamon, Oxford, 1987), Vol. 29.

${ }^{19}$ A. S. Kertes, in Metals in Mercury, Solubility Data Series, edited by C. Hirayama, Z. Galus, and C. Guminski (Pergamon, Oxford, 1986), Vol. 25.

${ }^{20}$ T. B. Massalski, Binary Alloy Phase Diagrams (Metals Park, Ohio, 1986), Vol. 2.

${ }^{21}$ J. Llopis, Catal. Rev. 2, 161 (1968).

${ }^{22}$ The dc current density $i_{\mathrm{dc}}$ in our experimental setup is assumed to be negligible compared to the applied ac current density, because no dc current was intentionally applied, and the dc current produced in the electrochemical cell when the electrical loop is closed is negligible due to the small surface area (below $1 \mathrm{~mm}^{2}$ ) of the platinum electrode.

${ }^{23}$ Extrapolating the $i_{\mathrm{dc}}=5 \mu \mathrm{A} / \mathrm{mm}^{2}$ data to a corrosion rate of $0.89 \mathrm{mg} /\left(\mathrm{mm}^{2}\right.$ h) leads to an ac current density $i_{\mathrm{ac}}$ of $61.2 \mathrm{~mA} / \mathrm{mm}^{2}$ very close to the ac current density used in our experiment $\left(63.3 \mathrm{~mA} / \mathrm{mm}^{2}\right)$. However, the $\mathrm{dc}$ current density in our experiment is zero, as mentioned, and the extrapolation of the $i_{\mathrm{dc}}=5 \mu \mathrm{A} / \mathrm{mm}^{2}$ data is therefore not appropriate, we believe.

${ }^{24}$ J. E. T. Andersen (private communication).

${ }^{25}$ R. C. Weast, CRC Handbook of Chemistry and Physics, 64th ed. (Chemical Rubber, Boca Raton, 1983).

${ }^{26}$ The penetration of oxygen into the platinum lattice is facilitated by the expansion of the metal lattice during the anodic or the anodic-cathodic potential (see Ref. 27).

${ }^{27}$ A. C. Chialvo, W. E. Tiraca, and A. J. Arvia, J. Electroanal. Chem. 140, 93 (1983).

${ }^{28}$ The enthalpy of formation of water is $-285.8 \mathrm{~kJ}$ per mole $\mathrm{H}_{2} \mathrm{O}$, (Ref 25), i.e., $2.96 \mathrm{eV}$ per formed water molecule $\mathrm{H}_{2} \mathrm{O}$. This released energy should be compared with the bond energy between two nearest neighbors of the face centered cubic platinum lattice of $0.30 \mathrm{eV}$ per bond, found simply by using the surface energy of a (100) facet of the platinum lattice of 2.48 $\mathrm{J} / \mathrm{m}^{2}$ (Ref. 29)

${ }^{29}$ H. L. Skriver and N. M. Rosengaard, Phys. Rev. B 46, 7157 (1992).

${ }^{30} \mathrm{~K}$. A. Christiansen (private communication).

${ }^{31}$ C. J. Smithells, Metals Reference Book, 5th ed. (Butterworths, London, 1976).

${ }^{32}$ A. H. Sørensen, Ph.D. thesis, Technical University of Denmark (November 1997). 